\title{
Urban-Rural Disparity of Generics Prescription in Taiwan: The Example of Dihydropyridine Derivatives
}

\author{
Chia-Chen Hsu, ${ }^{1}$ Chia-Lin Chou, ${ }^{1}$ Shu-Chiung Chiang, ${ }^{2}$ Tzeng-Ji Chen,,3 \\ Li-Fang Chou, ${ }^{4}$ and Yueh-Ching $\mathrm{Chou}^{1,5,6}$ \\ ${ }^{1}$ Department of Pharmacy, Taipei Veterans General Hospital, Taipei 11217, Taiwan \\ ${ }^{2}$ School of Medicine, Institute of Hospital and Health Care Administration, National Yang-Ming University, \\ Taipei 11221, Taiwan \\ ${ }^{3}$ Department of Family Medicine, Taipei Veterans General Hospital, Taipei 11217, Taiwan \\ ${ }^{4}$ Department of Public Finance, National Chengchi University, Taipei 11605, Taiwan \\ ${ }^{5}$ Department and Institute of Pharmacology, National Yang-Ming University, Taipei 11221, Taiwan \\ ${ }^{6}$ College of Pharmacy, Taipei Medical University, Taipei 11031, Taiwan
}

Correspondence should be addressed to Yueh-Ching Chou; ycchou@vghtpe.gov.tw

Received 4 November 2013; Accepted 3 January 2014; Published 10 February 2014

Academic Editors: P. P. Egeghy, A. Pacheco, and M. E. M. Peluso

Copyright (C) 2014 Chia-Chen Hsu et al. This is an open access article distributed under the Creative Commons Attribution License, which permits unrestricted use, distribution, and reproduction in any medium, provided the original work is properly cited.

\begin{abstract}
The aim of the current study was to investigate the urban-rural disparity of prescribing generics, which were usually cheaper than branded drugs, within the universal health insurance system in Taiwan. Data sources were the cohort datasets of National Health Insurance Research Database with claims data in 2010. The generic prescribing ratios of dihydropyridine (DHP) derivatives (the proportion of DHP prescribed as generics to all prescribed DHP) of medical facilities were examined against the urbanization levels of the clinic location. Among the total 21,606,914 defined daily doses of DHP, 35.7\% belonged to generics. The aggregate generic prescribing ratio rose from $6.7 \%$ at academic medical centers to $15.3 \%$ at regional hospitals, $29.4 \%$ at community hospital, and $66.1 \%$ at physician clinics. Among physician clinics, the generic prescribing ratio in urban areas was $63.9 \pm 41.0 \%$ (mean \pm standard deviation), lower than that in suburban $(69.6 \pm 38.7 \%)$ and in rural $(74.1 \% \pm 35.3 \%)$. After adjusting the related factors in the linear regression model, generic prescribing ratios of suburban and rural clinics were significantly higher than those of urban clinics ( $\beta=0.043$ and $0.077 ; P=0.024$ and 0.008 , resp.). The generic prescribing ratio of the most popular antihypertensive agents at a clinic was reversely associated with the urbanization level.
\end{abstract}

\section{Introduction}

Owing to geographic and socioeconomic factors, rural residents have usually less satisfactory access to various kinds of health care services than urban counterparts. In the past, many investigations into urban-rural disparity had been devoted to aspects of hospitalizations [1,2], surgical procedures [3], dental care [4], specialist care [5], emergency services $[6,7]$, preventive services $[8,9]$, nursing home care $[10,11]$, terminal care [12-15], complementary and alternative medicine use [16], and treatment outcomes [17]. The majority of these studies were related to undersupply of not easily transportable facilities and specialists in rural areas. In contrast, the urban-rural disparity in pharmaceutical care received less attention. A recent study about Medicare Part $\mathrm{D}$ in the USA had identified the role of branded drugs in regional variations of expenditure for prescription drugs [18]. However, extensive, detailed analyses of urban-rural disparity of generics prescription have not been well documented.

The aim of the current study was to investigate the urbanrural disparity of generics prescription within the universal health insurance system in Taiwan. The most popular antihypertensive drugs in the ambulatory sector would be analyzed as an example. Specifically for physician clinics, we would adjust patient, physician, and clinic features to measure the relationship between generic prescribing ratio and urbanization level of clinics. 


\section{Materials and Methods}

2.1. Ethics Statement. This study was approved by the institutional review board of Taipei Veterans General Hospital. Since the study was a retrospective medication record review and all data were deidentified, the review board approved that written consent from patients was not required.

2.2. Data Sources. The single-payer National Health Insurance (NHI) system in Taiwan started in 1995 and provides comprehensive healthcare coverage for more than $99 \%$ of inhabitants $(23,074,487$ beneficiaries at the end of 2010, equaling $99.6 \%$ of all population) [19]. Since 1999, the Bureau of NHI has released the claims data to the public for research purpose under the project of National Health Insurance Research Database (NHIRD) managed by the National Health Research Institutes [20]. To make a balance between privacy protection and longitudinal follow-ups, the NHIRD encrypted the identification numbers of persons and healthcare facilities in the datasets consistently for each applicant, so that record linking within datasets is feasible [21].

In the current study, we obtained one special subset of NHIRD, the Longitudinal Health Insurance Database for 2010 (LHID2010), that contained claims data belonging to one million people randomly sampled from all NHI beneficiaries in 2010. The claims data were traced back to 1996 and will be followed up afterwards. According to NHIRD, there was no significant difference in the age, gender distribution, and utilization between people in the LHID2010 and those in the complete NHIRD datasets. Our analysis was limited to the year 2010 with $15,431,528$ records of ambulatory visits plus $89,492,613$ prescribed items and 2,920,513 records at independent pharmacies plus 10,330,875 dispensed items. Not all prescribed drug items were dispensed at independent pharmacies in Taiwan because the outpatient departments at hospitals owned pharmacies and physician clinics were allowed to have dispensing practice if pharmacists were hired [22].

To identify the accreditation status and location of medical facilities, we used the registry for contracted medical facilities. The accreditation was divided into academic medical center, metropolitan hospital, local community hospital, and physician clinic. The location could be used to identify the governing branch of Bureau of NHI. The web site of the Bureau of NHI (http://www.nhi.gov.tw/) also provides the details of each reimbursable drug item, including the brand or generic status and the code of the Anatomical Therapeutic Chemical (ATC) classification system. The defined daily dose (DDD) of each ATC code was looked up on the web site of the WHO Collaborating Centre for Drug Statistics Methodology, Oslo, Norway (http://www.whocc.no/). The 2012 version was used for DDD calculation.

Additionally for calculating the covariates, we used the registry for medical personnel to have each prescribing physician's age, the monthly claim summary for ambulatory care claims to know the monthly service volume of each clinic, the registration files of beneficiaries to identify each patient's income, and the registry for catastrophic illness patients to learn whether a patient had a heavier illness.

2.3. Study Design. The drug group of dihydropyridine (DHP) derivatives (selective calcium channel blockers with mainly vascular effects) was the main focus of our study. According to the drug statistics from the Bureau of NHI, one of dihydropyridine derivatives, amlodipine, has remained the most popular antihypertensive agent and ranked as the first in pharmaceutical expenses with the NHI since 2000. From the drug master files of the Bureau of NHI, 203 drug items under the ATC coding of C08CA (dihydropyridine derivatives), C08GA01 (nifedipine and diuretics), and C10BX03 (atorvastatin and amlodipine) were identified for further analysis. Not all items were available at the market in 2010.

Within the NHI, physicians could write refill prescriptions entitling the patients to obtain one month's drug supply for three consecutive months. Because patients might not redeem every refill prescription, we extracted only the dispensed items of DHP, either at hospitals/clinics or at independent pharmacies, and the related prescribing details from the LHID2010 in 2010. Thus, prescribing in our study was represented with dispensed data. For each item, we identified its brand or generic status and calculated its dispensed amount in number of DDD. Besides, we also traced the prescribing physician and the medical facility. The identification number of the medical facility was then linked to the town where the facility was located. The urbanization level of a town was determined on the basis of a study conducted at the National Health Research Institutes in Taiwan and operationally categorized into urban, suburban, or rural [23].

In the current study, we firstly computed the aggregate amounts of all and generic DHP prescriptions and stratified the data by DHP ingredient to obtain an overview of the market for DHP within the NHI. The unit at calculating drug amounts was DDD. The aggregate data were further stratified by accreditation status and urbanization level of medical facilities. Specifically for all physician clinics, we examined the hypothesis that the generic prescribing ratio (the proportion of DHP prescribed as generics to all prescribed DHP) of a clinic was reversely associated with the urbanization level. The dependent variable was the generic prescribing ratio of a clinic. The independent variable was the urbanization level of a clinic. To take possible confounders into consideration, we also included as covariates the following factors: the prescribing physician's age, the governing branch of Bureau of NHI, the average monthly number of visits of a clinic, the average monthly amount of claims, the proportions of male patients, patients exempt from copayment and patients with a heavier illness certificate to all patients receiving DHP in a clinic, and the mean age and income of patients receiving DHP. If two or more physicians worked at the same clinic, we chose the physician in charge to calculate the prescribing physician's age of a clinic under the assumption that she/he had the deciding role in compiling the formulary in the clinic. The Bureau of NHI has six branches with separate budgets. The branches are divided according to geographic 
TABLE 1: Prescribing amount of DHP derivatives in one million beneficiaries within Taiwan's National Health Insurance in 2010, stratified by ingredient and branded/generic status.

\begin{tabular}{|c|c|c|c|c|c|c|c|c|c|}
\hline \multirow{2}{*}{ ATC code } & \multirow{2}{*}{ Ingredient } & \multicolumn{2}{|c|}{ All DHP } & \multicolumn{3}{|c|}{ Branded DHP } & \multicolumn{3}{|c|}{ Generic DHP } \\
\hline & & number of items & DDDs & number of items & DDDs & $(\%)$ & number of items & DDDs & $(\%)$ \\
\hline C08CA01 & Amlodipine & 33 & $13,491,768$ & 2 & $8,706,070$ & $(64.5)$ & 31 & $4,785,698$ & $\overline{(35.5)}$ \\
\hline C08CA02 & Felodipine & 20 & $2,737,174$ & 3 & $1,098,955$ & $(40.1)$ & 17 & $1,638,219$ & $(59.9)$ \\
\hline C08CA03 & Isradipine & 1 & 22,802 & 1 & 22,802 & $(100.0)$ & & & \\
\hline C08CA04 & Nicardipine & 8 & 11,064 & 3 & 6,253 & $(56.5)$ & 5 & 4,811 & $(43.5)$ \\
\hline C08CA05 & Nifedipine & 32 & $3,003,654$ & 6 & $2,139,413$ & $(71.2)$ & 26 & 864,241 & $(28.8)$ \\
\hline C08CA06 & Nimodipine & 2 & 1,024 & 2 & 1,024 & $(100.0)$ & & & \\
\hline С08CA07 & Nisoldipine & 2 & 3,437 & 2 & 3,437 & $(100.0)$ & & & \\
\hline C08CA08 & Nitrendipine & 4 & 94,027 & & & & 4 & 94,027 & $(100.0)$ \\
\hline С08CA09 & Lacidipine & 3 & 510,245 & 1 & 191,513 & $(37.5)$ & 2 & 318,732 & $(62.5)$ \\
\hline C08CA12 & Barnidipine & 2 & 53,606 & 2 & 53,606 & $(100.0)$ & & & \\
\hline C08CA13 & Lercanidipine & 1 & $1,339,212$ & 1 & $1,339,212$ & $(100.0)$ & & & \\
\hline \multicolumn{2}{|c|}{ C10BX03 Atorvastatin and amlodipine } & 1 & 338,903 & 1 & 338,903 & $(100.0)$ & & & \\
\hline \multicolumn{2}{|c|}{ Total } & 109 & $21,606,914$ & 24 & $13,901,187$ & $(64.3)$ & 85 & $7,705,727$ & $(35.7)$ \\
\hline
\end{tabular}

ATC: World Health Organization Anatomic Therapeutic and Chemical Classification; DHP: dihydropyridine; DDD: defined daily dose.

areas. The medical facilities governed by the same branch share the annual budget of healthcare expenses with a floating point value (monetary conversion factor) of reimbursement. Therefore, the governing branch of Bureau of NHI was listed into covariates.

2.4. Statistical Analysis. Data extraction and computation were performed with the Perl programming language (version 5.14.2). SPSS software (version 17) was used for statistical analysis. Pearson's $\chi^{2}$ test and analysis of variance (ANOVA) were used for group comparisons, respectively. Furthermore, we used linear regression models to compute all related measures and then adjust the other factors to test the relationship between generic prescribing ratio and urbanization level more accurately. A $P$ value $<0.05$ (two tailed) was considered as statistically significant.

\section{Results}

From the one-million person cohort datasets in 2010, we extracted 603,664 records of ambulatory visits with 614,334 prescribed items of DHP and 196,718 records at independent pharmacies with 198,392 dispensed items of DHP. After eliminating the unredeemed prescriptions, mainly as refill prescriptions, we obtained 750,087 prescribed/dispensed items for further analysis. These items had been prescribed to 88,900 patients by 19,156 physicians at 6,021 medical facilities. There were 109 distinct DHP items belonging to 12 ATC codes. Totally, 24 branded items accounted for 472,557 (63.0\%) prescribed items and 85 generics only for 277,530 (37.0\%). When the amount of prescriptions was expressed in DDD, 21,606,914 DDDs of DHP had been prescribed and generics accounted for $35.7 \%$ (Table 1). Amlodipine had the largest share $(62.4 \%)$ of the total DHP amount, followed by nifedipine (13.9\%) and felodipine (12.7\%).
When stratified by urbanization level of medical facilities, $67.4 \%(14,555,983 / 21,606,914)$ of the total DHP amount had been prescribed in urban areas, $25.8 \%$ in suburban, and $6.9 \%$ in rural (Table 2). When stratified by accreditation status of medical facilities, physician clinics accounted for $40.3 \%$ of the total DHP amount, followed by metropolitan hospitals $(24.1 \%)$, academic medical centers $(22.5 \%)$, and local community hospital (13.1\%). The aggregate generic prescribing ratio rose from $28.0 \%$ in urban areas to $66.5 \%$ in rural areas and from $6.7 \%$ at academic medical centers to $66.1 \%$ at physician clinics. Among physician clinics, the aggregate generic prescribing ratio rose from $61.0 \%$ in urban areas to $74.8 \%$ in rural areas.

To further examine the relationship between generic prescribing ratio and urbanization level in physician clinics, we calculated the individual generic prescribing ratio and other potential confounding factors of each physician clinic. The generic prescribing ratio of physician clinics in urban areas was $63.9 \pm 41.0 \%$ (mean \pm standard deviation), lower than that in suburban $(69.6 \pm 38.7 \%)$ and in rural $(74.1 \% \pm$ $35.3 \%$ ). The differences were statistically significant (Table 3 ). These three groups of physician clinics also differed in monthly visit count, monthly claims amount, the governing branch of Bureau of NHI, share of patients exempt from copayment, and average patients' age. In the regression model without adjustment, generic prescribing ratios of suburban and rural clinics were significantly higher than those of urban clinics ( $\beta=0.086$ and 0.150 resp.) (Table 4$)$. After adjusting the related factors which had no problematic collinearity, the strengths of relationship between generic prescribing ratio and urbanization level became smaller $(\beta=0.043$ and 0.077$)$ but were still statistically significant $(P=0.024$ and 0.008$)$.

\section{Discussion}

In recent years, most developed countries had faced the challenge of rising healthcare expenditure, of which drug costs 
TABLE 2: Aggregate prescribing amount of DHP derivatives in one million beneficiaries within Taiwan's National Health Insurance in 2010, stratified by accreditation status and urbanization level.

\begin{tabular}{|c|c|c|c|c|c|c|}
\hline & \multicolumn{6}{|c|}{ Accreditation status of medical facilities } \\
\hline & $\begin{array}{l}\text { Academic medical } \\
\text { centers }\end{array}$ & $\begin{array}{l}\text { Metropolitan } \\
\text { hospitals }\end{array}$ & $\begin{array}{l}\text { Local community } \\
\text { hospitals }\end{array}$ & Physician clinics & $\begin{array}{l}\text { Home care } \\
\text { units }\end{array}$ & Total \\
\hline \multicolumn{7}{|c|}{ Number of clinics } \\
\hline Urban & 20 & 54 & 182 & 2,921 & 5 & 3,182 \\
\hline Suburban & 1 & 27 & 131 & 1,945 & 1 & 2,105 \\
\hline Rural & & 2 & 28 & 704 & & 734 \\
\hline Total & 21 & 83 & 341 & 5,570 & 6 & 6,021 \\
\hline \multicolumn{7}{|c|}{ Amount of prescribed DHP in DDD } \\
\hline Urban & $4,857,576$ & $3,739,490$ & $1,571,777$ & $4,387,141$ & 200 & $14,555,983$ \\
\hline Suburban & 3,359 & $1,404,477$ & $1,055,655$ & $3,102,206$ & 60 & $5,565,696$ \\
\hline Rural & & 72,611 & 192,764 & $1,219,859$ & & $1,485,235$ \\
\hline Total & $4,860,934$ & $5,216,578$ & $2,820,195$ & $8,709,207$ & 260 & $21,606,914$ \\
\hline \multicolumn{7}{|c|}{ Amount of prescribed generic DHP in DDD } \\
\hline Urban & 324,538 & 646,557 & 428,388 & $2,675,767$ & 60 & $4,075,110$ \\
\hline Suburban & 0 & 148,519 & 330,358 & $2,164,702$ & 0 & $2,643,518$ \\
\hline Rural & & 3,825 & 70,550 & 912,724 & & 987,098 \\
\hline Total & 324,538 & 798,900 & 829,296 & $5,753,193$ & 60 & $7,705,727$ \\
\hline \multicolumn{7}{|c|}{ Generic prescribing ratio of DHP } \\
\hline Urban & $6.7 \%$ & $17.3 \%$ & $27.3 \%$ & $61.0 \%$ & $30.0 \%$ & $28.0 \%$ \\
\hline Suburban & $0.0 \%$ & $10.6 \%$ & $31.3 \%$ & $69.8 \%$ & $0.0 \%$ & $47.5 \%$ \\
\hline Rural & & $5.3 \%$ & $36.6 \%$ & $74.8 \%$ & & $66.5 \%$ \\
\hline Total & $6.7 \%$ & $15.3 \%$ & $29.4 \%$ & $66.1 \%$ & $23.1 \%$ & $35.7 \%$ \\
\hline
\end{tabular}

DDD: defined daily dose; DHP: dihydropyridine.

TABLE 3: Differences in generic prescribing ratio of DHP derivatives and other measures at physician clinics of various urbanization levels.

\begin{tabular}{|c|c|c|c|c|c|c|c|}
\hline & \multicolumn{6}{|c|}{ Urbanization level } & \multirow{3}{*}{$P$-value } \\
\hline & \multicolumn{2}{|c|}{$\operatorname{Urban}(n=2,921)$} & \multicolumn{2}{|c|}{ Suburban $(n=1,945)$} & \multicolumn{2}{|c|}{ Rural $(n=704)$} & \\
\hline & Mean & $\mathrm{SD}$ & Mean & $\mathrm{SD}$ & Mean & SD & \\
\hline Generic prescribing ratio (\%) & 63.85 & 40.97 & 69.57 & 38.67 & 74.13 & 35.25 & $<0.001^{\mathrm{c}}$ \\
\hline Prescribing physician's age & 52.09 & 10.08 & 52.07 & 10.18 & 52.24 & 11.19 & $0.923^{\mathrm{c}}$ \\
\hline Monthly visit count & $1,668.01$ & $1,716.78$ & $1,693.46$ & $1,257.96$ & $1,450.52$ & 932.91 & $0.001^{\mathrm{c}}$ \\
\hline Monthly claims amount & $836,357.00$ & $1,330,750.00$ & $769,430.30$ & $976,930.10$ & $584,243.70$ & 492066.20 & $<0.001^{\mathrm{c}}$ \\
\hline \multicolumn{8}{|l|}{ Branch of Bureau of NHI } \\
\hline Taipei & $1,136^{\mathrm{a}}$ & $79.5^{\mathrm{b}}$ & $255^{\mathrm{a}}$ & $17.84^{\mathrm{b}}$ & $38^{\mathrm{a}}$ & $2.66^{\mathrm{b}}$ & $<0.001^{\mathrm{d}}$ \\
\hline Northern & $414^{\mathrm{a}}$ & $54.98^{\mathrm{b}}$ & $308^{\mathrm{a}}$ & $40.9^{\mathrm{b}}$ & $31^{\mathrm{a}}$ & $4.12^{\mathrm{b}}$ & \\
\hline Middle & $432^{\mathrm{a}}$ & $35.56^{\mathrm{b}}$ & $617^{\mathrm{a}}$ & $50.78^{\mathrm{b}}$ & $166^{\mathrm{a}}$ & $13.66^{\mathrm{b}}$ & \\
\hline Southern & $329^{\mathrm{a}}$ & $35.04^{\mathrm{b}}$ & $383^{\mathrm{a}}$ & $40.79^{\mathrm{b}}$ & $227^{\mathrm{a}}$ & $24.17^{\mathrm{b}}$ & \\
\hline Kao-Ping & $574^{\mathrm{a}}$ & $53.2^{\mathrm{b}}$ & $340^{\mathrm{a}}$ & $31.51^{\mathrm{b}}$ & $165^{\mathrm{a}}$ & $15.29^{\mathrm{b}}$ & \\
\hline Eastern & $36^{\mathrm{a}}$ & $23.23^{\mathrm{b}}$ & $42^{\mathrm{a}}$ & $27.1^{\mathrm{b}}$ & $77^{\mathrm{a}}$ & $49.68^{\mathrm{b}}$ & \\
\hline Share of male patients (\%) & 48.22 & 30.13 & 47.15 & 27.56 & 45.75 & 24.65 & $0.091^{\mathrm{c}}$ \\
\hline Share of patients exempt from copayment (\%) & 8.50 & 17.98 & 8.33 & 19.55 & 25.19 & 38.47 & $<0.001^{c}$ \\
\hline Share of patients with a heavy illness (\%) & 7.44 & 16.79 & 7.06 & 15.08 & 7.76 & 13.31 & $0.548^{\mathrm{c}}$ \\
\hline Average patients' age & 60.17 & 8.47 & 61.52 & 8.28 & 64.43 & 6.71 & $<0.001^{\mathrm{c}}$ \\
\hline Average patients' income & $17,359.82$ & $15,114.28$ & $17,505.51$ & $11,564.02$ & $18,166.13$ & $7,346.10$ & $0.345^{\mathrm{c}}$ \\
\hline
\end{tabular}

DHP: dihydropyridine; NHI: National Health Insurance; SD: standard deviation.

a $n$.

$\mathrm{b}_{\%}$.

${ }^{c}$ ANOVA.

$\chi^{2}$ test. 
TABLE 4: Regression model of predicting the generic prescribing ratio of dihydropyridine (DHP) derivatives of a physician clinic with urbanization level and adjusting other factors.

\begin{tabular}{|c|c|c|c|c|c|c|}
\hline & \multicolumn{3}{|c|}{ Univariate } & \multicolumn{3}{|c|}{ Multivariate } \\
\hline & $\beta$ & SE & $P$-value & $\beta$ & SE & $P$-value \\
\hline \multicolumn{7}{|l|}{ Urbanization level } \\
\hline Urban & Reference & & & Reference & & \\
\hline Suburban & 0.086 & 0.019 & $<0.001$ & 0.043 & 0.019 & 0.024 \\
\hline Rural & 0.150 & 0.027 & $<0.001$ & 0.077 & 0.029 & 0.008 \\
\hline Prescribing physician's age & 0.005 & 0.001 & $<0.001$ & 0.004 & 0.001 & $<0.001$ \\
\hline Monthly visit count & 0.00001 & 0.00001 & 0.133 & 0.00005 & 0.00001 & $<0.001$ \\
\hline Monthly claims amount & -0.0000001 & 0.00000001 & $<0.001$ & -0.00000009 & 0.00000001 & $<0.001$ \\
\hline \multicolumn{7}{|l|}{ Branch of Bureau of NHI } \\
\hline Taipei & Reference & & & Reference & & \\
\hline Northern & 0.018 & 0.029 & 0.529 & 0.017 & 0.028 & 0.537 \\
\hline Middle & 0.152 & 0.026 & $<0.001$ & 0.160 & 0.026 & $<0.001$ \\
\hline Southern & 0.144 & 0.028 & $<0.001$ & 0.158 & 0.028 & $<0.001$ \\
\hline Kao-Ping & 0.105 & 0.026 & $<0.001$ & 0.118 & 0.026 & $<0.001$ \\
\hline Eastern & 0.393 & 0.055 & $<0.001$ & 0.385 & 0.054 & $<0.001$ \\
\hline Share of male patients & 0.0002 & 0.0003 & 0.510 & 0.001 & 0.0003 & 0.054 \\
\hline Share of patients exempt from copayment & -0.001 & 0.0004 & 0.008 & -0.0002 & 0.0004 & 0.650 \\
\hline Share of patients with a heavy illness & -0.003 & 0.001 & $<0.001$ & -0.001 & 0.001 & 0.015 \\
\hline Average patients' age & -0.003 & 0.001 & 0.005 & -0.004 & 0.001 & $<0.001$ \\
\hline Average patients' income & -0.000002 & 0.000001 & 0.002 & -0.000003 & 0.000001 & $<0.001$ \\
\hline
\end{tabular}

$\beta$ : regression coefficient; SE: standard error; NHI: National Health Insurance.

accounted for a large share. Beside aging demographic structure, the pharmaceutical innovation was usually considered as a cost factor. Therefore, one of frequently implemented measures of controlling drug costs was to encourage the use of cheaper generics [24-26]. While the majority of researches into generics switch or substitution disputed about the drug quality, our current study touched the issue of equity. Our results revealed that generics of DHP were far less frequently prescribed at outpatient departments of hospitals than at physician clinics in Taiwan. Because most hospitals, also larger ones, were located in urban areas, our further analysis on physician clinics confirmed the urban-rural disparity of generic prescribing in Taiwan.

In our study, the aggregate generic prescribing ratio of DHP was $35.7 \%$. In a US study about the Medical Expenditure Panel Survey Household Component from 1997 to 2000, $61 \%$ of drugs at outpatient sector were dispensed as generics [24]. In another US study about paid pharmacy claims from 548 self-insured employers, the aggregate generic prescribing ratio also was high as $63.3 \%$ at the end of 2009 . In contrast, the aggregate generic prescribing ratio of DHP in Taiwan was relatively low despite the availability of 85 generics in all 109 distinct items. The late expiry of patent of amlodipine that occurred in 2007 did not seem to be able to fully explain the phenomenon. As compared to $35.5 \%$ of amlodipine, the generic prescribing ratio of the older nifedipine was even lower (28.8\%) (Table 1).

In the discussions about the determinants of physician use of generic or new drugs, financial incentives were frequently mentioned $[27,28]$. At least for physicians working at hospitals who could only prescribe drugs according to hospital formulary, the financial incentives might originate from hospital administrators instead of physicians. In our study, the average generic prescribing ratio of DHP at physician clinics in urban areas was lower than those at suburban and rural. One of potential determinants that were not listed as confounders in data adjustment was competition, among physician clinics on one hand and between physicians and neighboring hospitals on the other hand. The factor of competition was also reflected in the comparisons of generic prescribing ratio of DHP at physician clinics under different branches of Bureau of NHI. In most densely populated regions where Taipei and Northern branches are located, generic prescribing ratios were the lowest. In contrast, the ration was the highest in most sparsely populated eastern Taiwan (Table 4).

Some other factors were unmentioned in our current study, but they also remained unknown. Because physician clinics were allowed to dispense drugs in Taiwan, physicians at dispensing clinics did face financial benefits on drug choice. However, the margin of drugs, that is, the difference between the buying cost and the reimbursement from NHI, could not be known for each drug at every clinic. This factor would be further compounded by the phenomenon of "next-door pharmacy" in Taiwan, in which a physician clinic operated the neighboring pharmacy instead of hiring a pharmacist in-house [22]. Logistics of drugs were another factor hard to decipher. Although the manufacturers were specified for each drug item in the master file, the drugs were usually merchandized through distributors, especially 
for practicing clinics. The assortment of drugs available at a distributor would also limit the drug choice of medical facilities. The situation was conceivably more severe in rural areas where few distributors might offer services.

\section{Conclusions}

The generic prescribing ratio of the most popular antihypertensive agents at a clinic was reversely associated with the urbanization level. The underlying causes, clinical consequences, and economic justice of urban-rural disparity in prescribing generics deserve further investigation.

\section{Conflict of Interests}

The authors declare that they have no conflict of interests in the study.

\section{Acknowledgments}

This study is based on part of data from the National Health Insurance Research Database provided by the Bureau of National Health Insurance, Department of Health and managed by National Health Research Institutes. The interpretation and conclusions contained herein do not represent those of Bureau of National Health Insurance, Department of Health or National Health Research Institutes.

\section{References}

[1] K. Rost, S. Adams, S. Xu, and F. Dong, "Rural-urban differences in hospitalization rates of primary care patients with depression," Psychiatric Services, vol. 58, no. 4, pp. 503-508, 2007.

[2] J. M. Thorpe, C. H. van Houtven, B. L. Sleath, and C. T. Thorpe, "Rural-urban differences in preventable hospitalizations among community-dwelling veterans with dementia," Journal of Rural Health, vol. 26, no. 2, pp. 146-155, 2010.

[3] M. L. Francis, S. L. Scaife, and W. E. Zahnd, "Rural-urban differences in surgical procedures for Medicare beneficiaries," Archives of Surgery, vol. 146, no. 5, pp. 579-583, 2011.

[4] K. A. Levin, C. A. Davies, G. V. A. Douglas, and N. B. Pitts, "Urban-rural differences in dental caries of 5-year old children in Scotland," Social Science \& Medicine, vol. 71, no. 11, pp. 20202027, 2010.

[5] D. L. Kok, J.-H. Chang, B. Erbas et al., "Urban-rural differences in the management of screen-detected invasive breast cancer and ductal carcinoma in situ in Victoria," ANZ Journal of Surgery, vol. 76, no. 11, pp. 996-1001, 2006.

[6] N. Huang, W. Yip, H.-J. Chang, and Y.-J. Chou, "Trends in rural and urban differentials in incidence rates for ruptured appendicitis under the National Health Insurance in Taiwan," Public Health, vol. 120, no. 11, pp. 1055-1063, 2006.

[7] E. C. Leira, D. C. Hess, J. C. Torner, and H. P. Adams Jr., "Rural-urban differences in acute stroke management practices: a modifiable disparity," Archives of Neurology, vol. 65, no. 7, pp. 887-891, 2008.

[8] S. Larson and R. Correa-de-Araujo, "Preventive health examinations: a comparison along the rural-urban continuum," Women's Health Issues, vol. 16, no. 2, pp. 80-88, 2006.
[9] V. Stamenić and M. Strnad, "Urban-rural differences in a population-based breast cancer screening program in Croatia," Croatian Medical Journal, vol. 52, no. 1, pp. 76-86, 2011.

[10] W. J. McAuley, W. Spector, and J. van Nostrand, "Formal home care utilization patterns by rural-urban community residence," Journals of Gerontology B, vol. 64, no. 2, pp. 258-268, 2009.

[11] C. E. Gessert, I. V. Haller, R. L. Kane, and H. Degenholtz, "Ruralurban differences in medical care for nursing home residents with severe dementia at the end of life," Journal of the American Geriatrics Society, vol. 54, no. 8, pp. 1199-1205, 2006.

[12] D. Goodridge, J. Lawson, D. Rennie, and D. Marciniuk, "Rural/urban differences in health care utilization and place of death for persons with respiratory illness in the last year of life," Rural and Remote Health, vol. 10, no. 2, article 1349, 2010.

[13] H.-C. Lin, Y.-J. Lin, T.-C. Liu, C.-S. Chen, and C.-C. Lin, "Urbanization and place of death for the elderly: a 10-year population-based study," Palliative Medicine, vol. 21, no. 8, pp. 705-711, 2007.

[14] V. H. Menec, S. Nowicki, and A. Kalischuk, "Transfers to acute care hospitals at the end of life: do rural/remote regions differ from urban regions?" Rural and Remote Health, vol. 10, no. 1, article 1281, 2010.

[15] D. Waldrop and A. M. Kirkendall, "Rural-urban differences in end-of-life care: implications for practice," Social Work in Health Care, vol. 49, no. 3, pp. 263-289, 2010.

[16] J. Adams, D. Sibbritt, and C.-W. Lui, "The urban-rural divide in complementary and alternative medicine use: a longitudinal study of 10,638 women," BMC Complementary \& Alternative Medicine, vol. 11, article 2, 2011.

[17] M. Coory, M. Smithers, J. Aitken, P. Baade, and I. Ring, "Urbanrural differences in survival from cutaneous melanoma in Queensland," Australian and New Zealand Journal of Public Health, vol. 30, no. 1, pp. 71-74, 2006.

[18] J. M. Donohue, N. E. Morden, W. F. Gellad et al., "Sources of regional variation in Medicare part D drug spending," The New England Journal of Medicine, vol. 366, no. 6, pp. 530-538, 2012.

[19] Bureau of National Health Insurance, Department of Health, Executive Yuan, "The National Health Insurance Statistics," 2010, http://www.nhi.gov.tw/English/webdata/webdata.aspx? menu=11\&menu_id=296\&WD_ID=296\&webdata_id=4010.

[20] Y.-C. Chen, H.-Y. Yeh, J.-C. Wu, I. Haschler, T.-J. Chen, and T. Wetter, “Taiwan's National Health Insurance Research Database: administrative health care database as study object in bibliometrics," Scientometrics, vol. 86, no. 2, pp. 365-380, 2011.

[21] C.-Y. Tu, T.-J. Chen, and L.-F. Chou, "Application of frequent itemsets mining to analyze patterns of one-stop visits in Taiwan," PLoS ONE, vol. 6, no. 7, Article ID e14824, 2011.

[22] T. J. Chen, L.-F. Chou, and S. J. Hwang, "Application of concentration ratios to analyze the phenomenon of "next-door" pharmacy in Taiwan," Clinical Therapeutics, vol. 28, no. 8, pp. 1225-1230, 2006.

[23] C. Y. Liu, Y. T. Hung, Y. L. Chung et al., "Incorporating development stratification of Taiwan townships into sampling design of large scale health interview survey," Journal of Health Management, vol. 4, no. 1, pp. 1-22, 2006.

[24] J. S. Haas, K. A. Phillips, E. P. Gerstenberger, and A. C. Seger, "Potential savings from substituting generic drugs for brandname drugs: medical expenditure panel survey, 1997-2000," Annals of Internal Medicine, vol. 142, no. 11, pp. 891-897, 2005.

[25] J. N. Liberman and M. C. Roebuck, "Prescription drug costs and the generic dispensing ratio," Journal of Managed Care Pharmacy, vol. 16, no. 7, pp. 502-506, 2010. 
[26] C.-L. Chen, L. Chen, and W.-C. Yang, "The influences of Taiwan's generic grouping price policy on drug prices and expenditures: evidence from analysing the consumption of the three most-used classes of cardiovascular drugs," BMC Public Health, vol. 8, article 118, 2008.

[27] Y.-M. Liu, Y.-H. Yang, and C.-R. Hsieh, "Financial incentives and physicians' prescription decisions on the choice between brand-name and generic drugs: evidence from Taiwan," Journal of Health Economics, vol. 28, no. 2, pp. 341-349, 2009.

[28] Y.-M. Liu, Y.-H. Yang, and C.-R. Hsieh, "The determinants of the adoption of pharmaceutical innovation: evidence from Taiwan," Social Science \& Medicine, vol. 72, no. 6, pp. 919-927, 2011. 


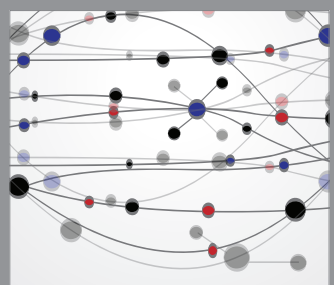

The Scientific World Journal
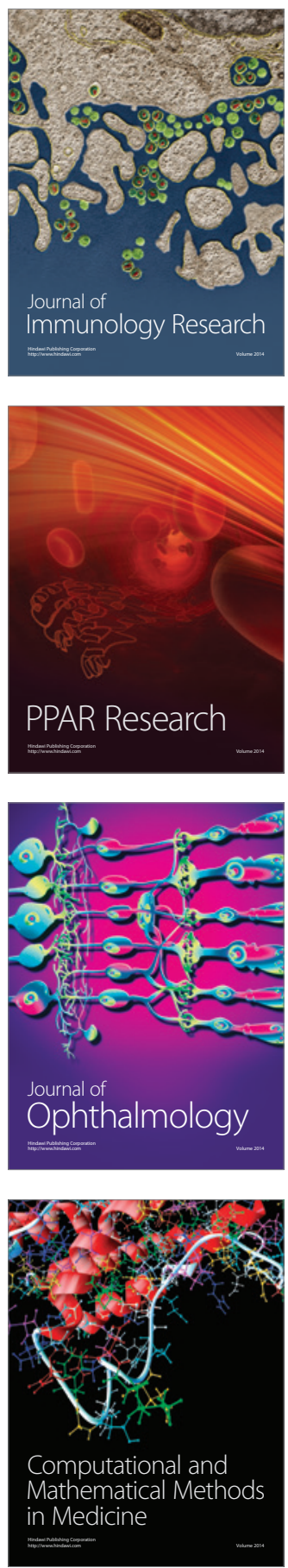

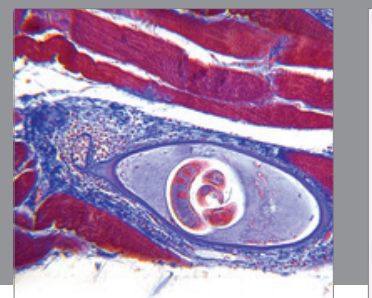

Gastroenterology

Research and Practice
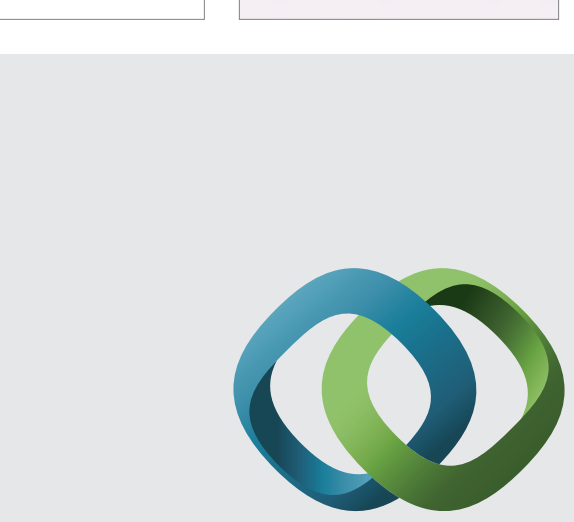

\section{Hindawi}

Submit your manuscripts at

http://www.hindawi.com
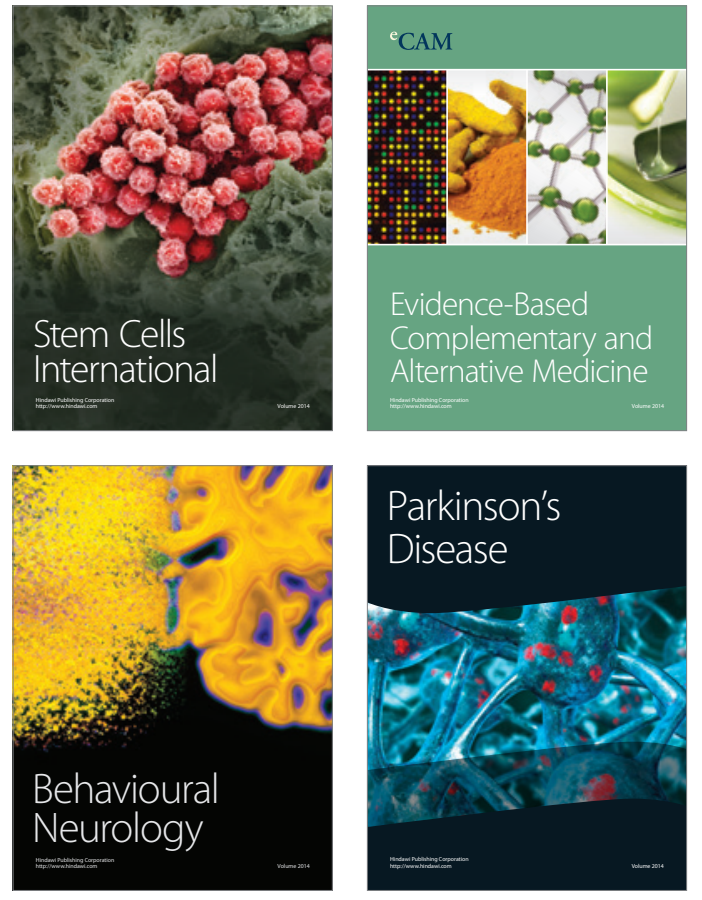
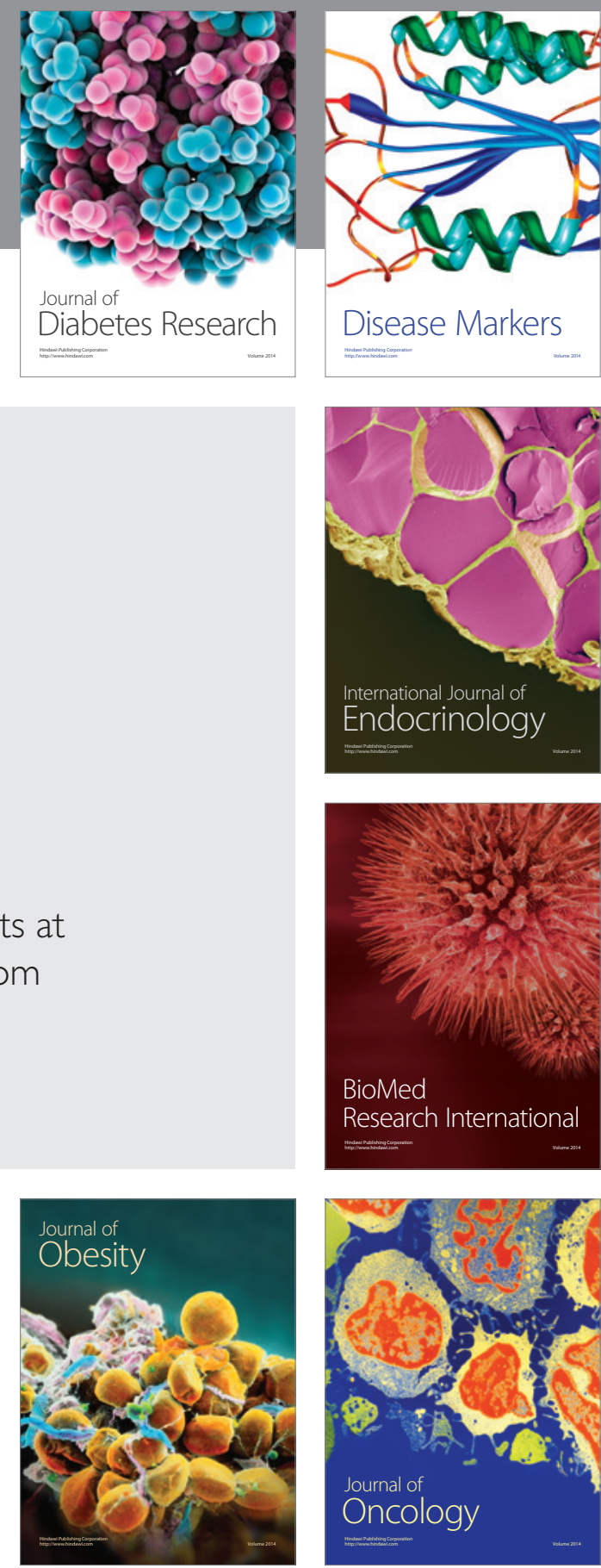

Disease Markers
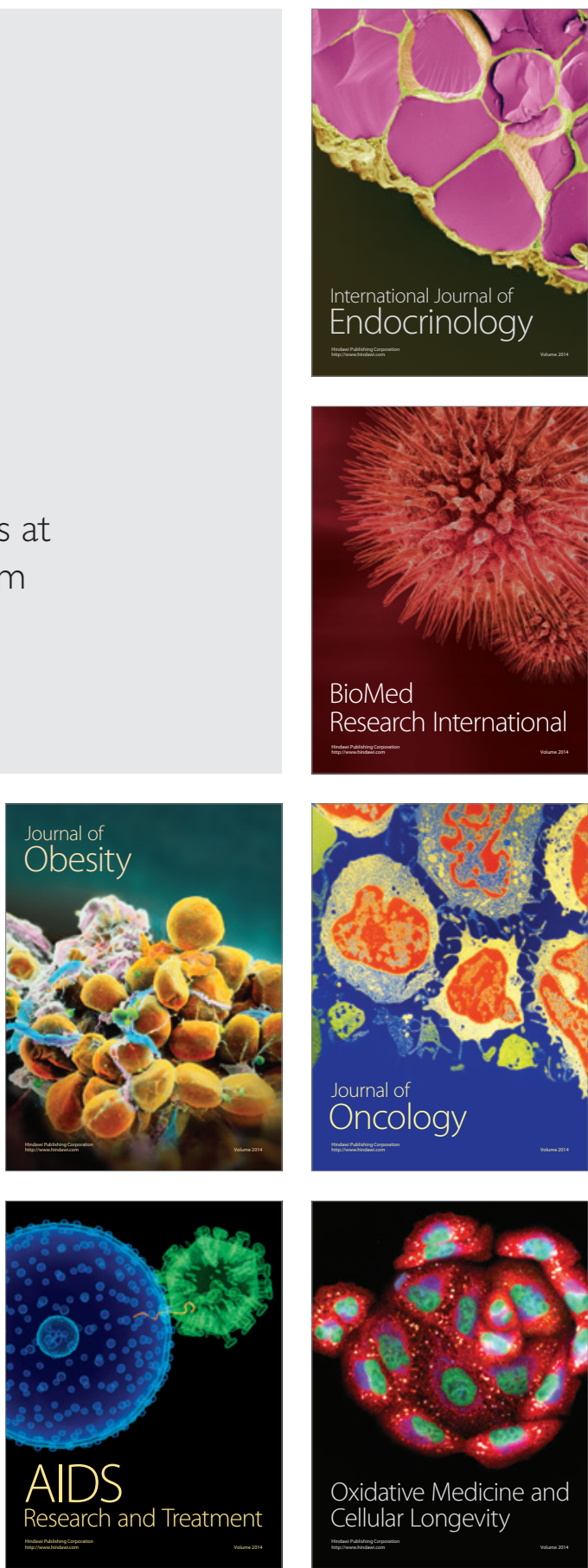